\title{
Management of stomal complications
}

\author{
SVANTE R NORDGREN MD PHD
}

\begin{abstract}
SR NORDGREN. Management of stomal complications. Can J Gastroenterol 1995;9(1):27-32. Creation of an intestinal stoma, be it temporary or permanent, requires good judgement and surgical skill. For the patient the stoma is of constant concern, and a well constructed intestinal stoma can reduce the patient's physical and psychological stress. Peristomal skin irritation should alert a search for surgical complications. Collaboration with an enterostomal therapist is strongly advised. The probability of revision of an ileostomy during the first 10 years reaches 0.44 in patients with ulcerative colitis (UC) and 0.75 in patients with Crohn's disease (CD). The most frequently seen complication are stenosis and sliding retraction. Stomal fistulas are seen more frequently in patients with CD than those with UC. Most ileostomy complications can be treated locally, without a laparotomy. The sigmoid colostomy, a stoma of the elderly, is also frequently complicated by stenosis, particularly after postoperative infection and separation at the mucocutaneous junction. Peristomal herniation is extremely common, and some degree of herniation is almost inevitable. There are no randomized studies to determine the best way to construct a colostomy. Bringing the bowel through the rectus muscle is probably superior to lateral to the muscle. Extraperitoneal colostomy does not provide any advantage over the intraperitoneal route. A colostomy stenosis is best managed locally. Infectious complications and hernias require laparotomy and resiting of the stoma.
\end{abstract}

Key Words: Colostomy, Ileostomy, Inflammatory bowel disease, Stomal complications

\section{Traitement des complications de stomie}

RÉSUMÉ : La stomie, qu'elle soit temporaire ou permanente, exige un bon jugement clinique et une bonne technique chirurgicale. Pour le patient, la stomie est une préoccupation constante et si elle est bien faite, le stress tant physique que psychologique auquel le patient est exposé, sera moindre. L'irritation de la peau autour de la stomie peut signaler un risque de complication chirurgicale. Une

voir page suivante

Department of Surgery, The Colorectal Unit, University of Göteborg, Göteborg, Sweden Correspondence: Dr SR Nordgren, University of Göteborg, Department of Surgery, The Colorectal Unit, Sahlgrenska Sjukhuset, S-413 45 Göteborg, Sweden

This paper was presented at the Trends in Inflammatory Bowel Disease Therapy meeting, April 6 to 9, 1994, held in Victoria, British Columbia. This paper has also been published in Sutherland LR, et al, eds. Inflammatory Bowel Disease: Basic Research, Clinical Implications and Trends in Therapy. Boston, Dordrecht and London: Kluwer Academic Publishers, 1994
$A_{\text {constant concern to anyone who }}^{\text {n intestinal stoma is of }}$ has one. However, a well constructed intestinal stoma can reduce the physical and psychological stress on its bearer. Creation of an intestinal stoma, be it temporary or permanent, therefore requires good judgement and surgical skill. However complicated or difficult the intra-abdominal part of the operation that necessitated the stoma, it is the quality and function of the stoma that determines a significant part of the long term quality of life. Problems related to the stoma must be specifically searched for because these kinds of problems are not always revealed spontaneously.

A short survey of stomal complications and their management will be reviewed and discussed.

\section{TERMINAL ILEOSTOMY}

A terminal ileostomy is the temporary or permanent result after proctocolectomy for patients mainly with ulcerative colitis, Crohn's disease and familial adenomatous polyposis. In ulcerative colitis and familial adenomatous polyposis, a terminal ileostomy may be avoided by means of sphinctersaving reconstructive surgery. This is rarely so in Crohn's disease.

A correctly situated, well constructed and properly managed Brooke ileostomy (1) should, at least from a physical point of view, allow the patient to live an almost normal life. 
étroite collaboration avec un stomathérapeute est fortement conseillée. La probabilité d'une révision d'iléostomie au cours des dix premières années atteint 0,44 chez les patients qui souffrent de colite ulcéreuse et 0,75 chez les patients atteints de maladie de Crohn. Les complications les plus souvent observées sont la sténose et la rétraction par glissement. Les fistules de stomie s'observent plus fréquemment chez les patients atteints de maladie de Crohn que chez ceux qui souffrent de colite ulcéreuse. La plupart des complications d'iléostomie peuvent être traitées localement sans laparotomie. La colostomie au niveau du sigmoïde effectuée chez les gens âgés se complique souvent aussi de sténose, particulièrement après une infection postopératoire et une séparation de la jonction mucocutanée. L'hernie qui touche la stomie est extrêmement fréquente et presque inévitable jusqu'à un certain point. Aucune étude randomisée n'a été effectuée pour déterminer la meilleure façon de construire une colostomie. Il est probablement préférable de passer à travers le grand droit qu'à côté de ce dernier. La colostomie extrapéritonéale n'offre aucun avantage par rapport à la colostomie intrapéritonéale. Une sténose de la colostomie se traite plus efficacement localement; les complications infectieuses et les hernies exigent une laparotomie et une relocalisation de la stomie.

TABLE 1

Indications for ileostomy revision (collected series from references 4,8 and 25)

\begin{tabular}{lc}
\hline Indication & Total (\%) \\
\hline Retraction & $87(35)$ \\
Stenosis & $74(30)$ \\
Prolapse & $25(10)$ \\
Fistula & $24(10)$ \\
Miscellaneous & $38(15)$ \\
\hline
\end{tabular}

However, stomal complications do occur and frequently necessitate the need for revisional surgery.

Despite modern measures for skin protection and modern appliances, peristomal skin irritation is the most common complication, and most patients occasionally suffer from this inconvenience $(2,3)$. Whenever skin irritation develops, its cause should be identified, preferably in conjunction with an enterostomal therapist. An algorithm for the analysis of stomal complications is given in Figure 1.

Peristomal irritation of the skin is most often a result of repeated exposure to stomal contents, although sensitization to the appliance has to be ruled out. Repeated leakage may depend on imperfections in handling of the appliance or, more often, local conditions that make fitting of the appliance difficult. An inappropriately sited stoma, an abdominal scar or a skin fold may be present or the stoma may be subject to a surgical complication. To avoid the disability of stomal dysfunction it is important that surgically correctable problems are identified and surgical revision undertaken.

The surgical revision rate in a collected series of 2530 patients with ul- cerative colitis, mainly based on questionnaires, was $19.3 \%$ (4-8). The revision rate increases with time and interest spent in searching for stomal problems. According to the author's experience, the cumulative risk of needing at least one revision after 10 years reached 0.75 in Crohn's disease and 0.44 in ulcerative colitis (8) (Figure 2). The increased risk in Crohn's disease compared with ulcerative colitis was verified by others $(6,9)$ but not all (10). The relative frequencies of various surgical complications appear in Table 1.

\section{ILEOSTOMY COMPLICATIONS}

Early ileostomy necrosis: Significant early edema of the postoperative ileostomy is common, and ischemia with sloughing of the mucosa sometimes occurs. Fortunately, early postoperative necrosis of the ileostomy is an uncommon complication. The most common cause is a too narrow opening in the abdominal wall. However, in a patient with low cardiac output or mesenteric vascular occlusion it may be a part of total intestinal ischemia. The author suggests that if there is any concern as to the viability of the ileostomy at its construction, the abdomen should not be closed until the stoma is satisfactorily matured.

Stenosis: Even when constructed according to modern principles, ileostomy stenosis is still one of the most common long term complications. Normally the ileal stoma should accept passage of the distal part of the fifth ("little') finger. However, a symptomatic

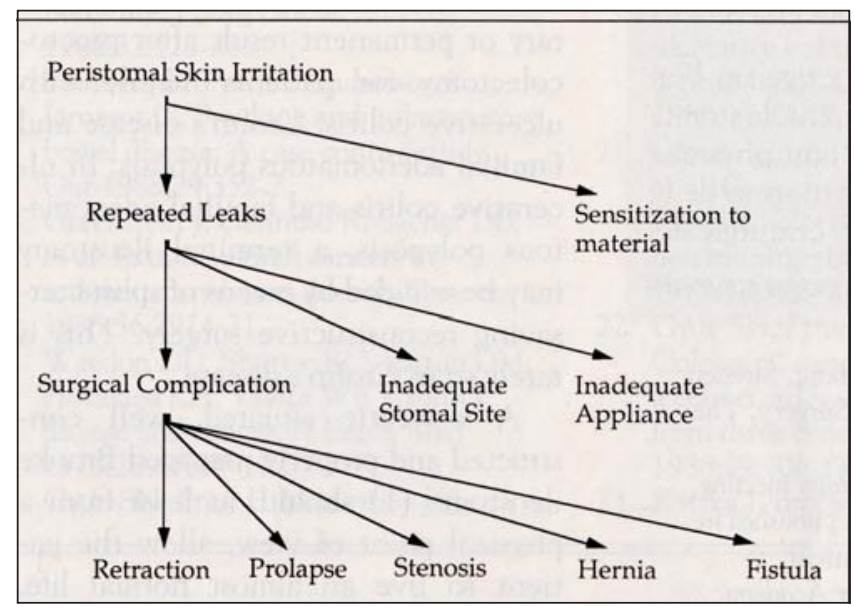

Figure 1) Algorithm for assessment of ileostomy dysfunction

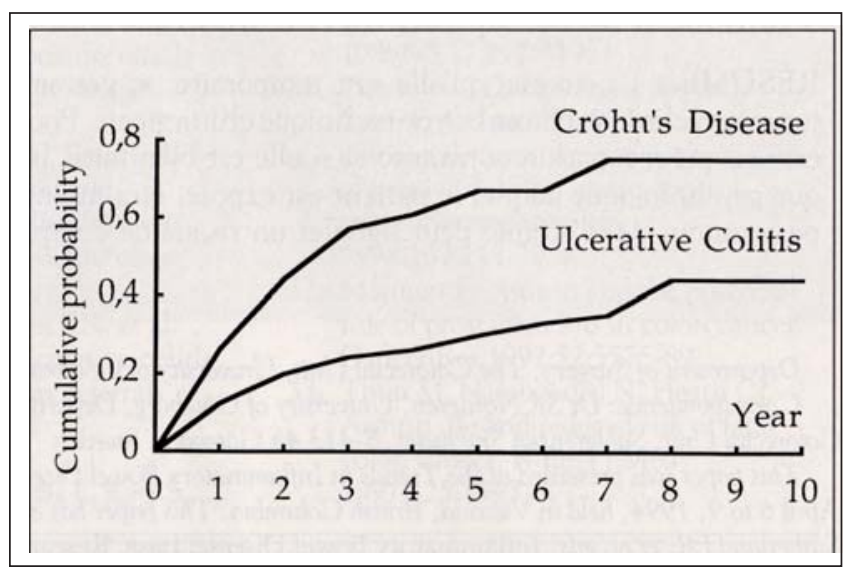

Figure 2) Cumulative probability of need for the first ileostomy revision in patients with ulcerative colitis and Crohn's disease 
stenosis does not occur until the stoma is quite narrow. This condition usually causes intermittent ileostomy discharge, pain at passage of undigested food material or even total stomal obstruction. The stenosis is almost invariably located at the skin level and the size of the skin opening can easily be gauged by the examining finger.

Stenosis is an unpredictable complication. After secondary healing of the mucocutaneous junction a stenosis is to be expected. In most patients it cannot be predicted, and stenosis occurs regularly in some patients and not at all in others. Repeated instrumental dilation does not prevent development of a stenosis and may even worsen the condition. Treatment of a tight ileostomy stenosis involves excision of peristomal skin and re-establishment of the mucocutaneous junction. This operation may be done under local infiltration but general anesthesia is usually preferred by patients.

Prolapse: In patients with less ability to form peritoneal adhesions, a sliding prolapse may occur on forceful straining, such as heavy lifting. A prolapse can also develop over time. Secondary inflammatory changes may occur and a sliding prolapse becomes fixed. A fixed 'prolapse' may also be a stoma that was constructed too long. Surgical correction is necessary. Both the sliding and the fixed prolapse are repaired by excision of the stoma, close to the mucocutaneous junction to avoid enlargement of the skin opening, desussception of the stoma, amputation of its distal part, fixation to the abdominal aponeurosis and resuturing of the mucocutaneous junction.

Retraction: A retraction may be fixed or sliding. The pathophysiology behind sliding retraction is probably similar to that of a sliding prolapse. As stated above, a sliding stoma is frequently seen in patients who don't form peritoneal adhesions. Retraction of the stoma may also occur in patients who have gained weight. A retracted and flat stoma causes leakage of ileostomy fluid under the appliance with subsequent skin irritation.

Correction of stomal retraction involves peristomal incision and dissec- tion of the small bowel all the way into the peritoneal cavity so that sufficient length can be mobilized through the abdominal opening. The terminal bowel is carefully sutured to the abdominal parietes, the stoma everted and mucocutaneous sutures applied. If necessary, note that a $5 \mathrm{~mm}$ wide disc of skin can be nourished by small bowel perfusion and re-establishment of the stoma can be done by suturing the peristomal disk of skin to the peristomal skin.

Speakman and co-workers (11) advocated the use of a linear stapler (TEA 55 or the S-GIA) to control sliding retraction. Anesthesia was not necessary. Their results appear less convincing, however, because a considerable number of postoperative problems occurred, such as stomal edema and bleeding. Three of 10 patients developed abscess, ulcerations and sepsis.

Ulceration and fistula formation: According to our experience, stomal ulcers and fistulas occur more frequently in patients with Crohn's disease than in ulcerative colitis patients, even when recurrent Crohn's disease is excluded. The etiology of stomal fistulas varies although a stomal ulcer or peristomal abscess is frequently involved in the pathogenesis. Recurrent Crohn's disease should be excluded by endoscopy. If an abscess or cavity is found it should be drained before permanent repair.

When the fistulous tract involves subcutaneous tissue around the stoma it is probably safe to relocate the stoma and to leave the skin of the old stomal opening and the fistulous tract open to granulation and secondary healing (12). If the fistula is distal to the skin level, as a perforation of the extra-abdominal ileal spout, a local procedure may be sufficient (2).

Ulcers or granulomas are most often observed on the caudal aspect of the ileostomy. A decubital ulcer from an appliance that is not properly cut or fixed should be suspected. The appliance should be assessed in collaboration with an enterostomal therapist. Secondary changes from long-standing ulcerations on the ileostomy may necessitate resection and construction of a new stoma.
Ileostomy hernia: Subcutaneous herniation at the site of an ileostomy is less common, particularly compared with the incidence of colostomy hernia (see below). Herniation interferes greatly with ileostomy management and is associated with sore skin and leakage. Moreover, subcutaneous kinking of the bowel in a hernia may cause episodes of obstruction.

Local revision may be successful but resiting the ileostomy, usually to the other side of the abdomen, may be required for satisfactory results. A snugly fitted belt may be a temporary solution.

Prestomal ileitis: Prestomal ileitis implies an inflammation of the prestomal mucosa. The principal symptoms are increased ileostomy discharge, watery consistency of the stools, pain in the peristomal area and sometimes blood in the stools. Extensive inflammation may cause peristomal abscess formation with fistulization of the peristomal skin. Intra-abdominal perforation may occur. Short segments of prestomal inflammation can be observed incidentally without any symptoms.

Before the Brooke ileostomy came into practice, inflammation of the prestomal ileum was most often seen as a result of stenosis of the stoma. The condition is difficult to distinguish from recurrent Crohn's disease.

Miscellaneous: Peristomal varicose veins are observed in patients with portal hypertension. Bleeding is the major problem, particularly when there is irritation to the peristomal skin. Bleeding may be profuse and cross-stitch suture may be necessary for control. Measures to reduce the portal pressure should be considered. Cancer in the ileostomy has been observed in an extended follow-up of patients with ileostomy (13), and should be suspected in ulcers of the mucocutaneous junction.

\section{LOOP ILEOSTOMY}

The loop ileostomy is a useful alternative to a defunctioning colostomy in elective colorectal surgery, or in an emergency operation when diversion of the fecal stream from the large bowel is required $(14,15)$. It is also useful for protection of an ileorectal anastomosis 
or an ileal reservoir. This stoma is normally supported by a short rod and only sutured to the skin, without sutures to the abdominal wall. When the supporting rod is removed, on day 7 postoperatively, granulation tissue keeps the stoma in place. Turning the ileal loop so the active part of the stoma opens distally reduces the risk of skin irritation (15), an opinion not shared by all (14).

For the six to 10 weeks the loop ileostomy normally is required there are few problems with stability. If for any reason the loop ileostomy is retained longer than that, sliding retraction or prolapse occur. If this is the case, closure of the ileostomy or conversion to a terminal end-ileostomy, with subcutaneous or intra-abdominal closure of the distal part, should be considered.

Complications necessitating surgical revision are rare. If a complication does occur, closure of the loop ileostomy should be considered if possible. If not, it should be converted to a terminal ileostomy.

Hospitalization for high ostomy output was reported by Wexner et al (14) in four of 83 patients, and in 23 of 117 patients by Feinberg et al (16). Monitoring of urinary sodium excretion may help to predict which patients are at risk (17).

\section{TRANSVERSE COLOSTOMY}

The transverse colostomy is used for fecal diversion in left colonic obstruction or for protection of a colorectal anastomosis. Because of intercurrent medical problems in the group of patients at risk of a left colonic obstruction this stoma is often retained for the rest of the patient's life. From a functional point of view the transverse colostomy is a less favourable alternative for the patient. This stoma combines the problems of a colostomy (fecal odour) with the problems of an ileostomy (increased water loss and irritant action to the skin).

Furthermore, the stoma is usually inconveniently located immediately below the right costal margin where it interferes with clothing. Complications such as prolapse and peristomal hernia are common.
Prolapse of the transverse colostomy, creating the typical 'ox horn' appearance, is most frequently encountered when the stoma is retained for more than two months (18). Adequate treatment is closure of the stoma or conversion to an alternative enterostomy when possible.

The author suggests that the transverse colostomy be avoided. Should it be necessary, a more convenient place for the stoma than the subcostal region should be tried, and construction of a terminal colostomy with primary eversion of the active, proximal limb and closure of the distal limb should be considered.

\section{TERMINAL SIGMOID COLOSTOMY}

The sigmoid colostomy is usually constructed in conjunction with an abdominoperineal resection for rectal cancer or as a Hartmann procedure for complicated diverticulitis. Patients are often in their 60 s or older. The operative procedure is often performed by young surgeons as an emergency procedure when full expertise is not at hand. Construction is often difficult due to obesity, a fat mesentery and multiple diverticula, and normal healing is frequently impaired. Due to the poor general condition of the patients, postoperative rehabilitation is prolonged. Patients with a sigmoid colostomy are often unable to manage the stoma on their own, which makes the colostomy a matter of concern for the family, relatives or home care personnel.

Colostomy complications were investigated by Cubertafond and colleagues (19) based on a review of 4320 patients, including 1142 personal cases, $78 \%$ of which had a stoma of the left colon. The most common early complication was peristomal infection with separation (10 to $25 \%$ ). Late complications were seen in 7 to $56 \%$ of patients. The most commonly seen late complications were hernia, prolapse and stenosis.

\section{COMPLICATIONS OF THE SIGMOID COLOSTOMY}

Early colostomy necrosis: Necrosis of the terminal part of the colon may oc- cur due to faulty judgement of the adequacy of its blood supply. Normal perfusion may be reduced by compression through the stomal wound due to a fatty mesentery or inflammatory edema in the mesocolon. Should necrosis develop, the level of viable bowel should be established by inspection or careful endoscopy. If ischemic changes extend to the level of the aponeurosis, early relaparotomy and reconstruction of the stoma should be considered to avoid intra-abdominal fecal leakage. An immediate reconstruction of a colostomy can be performed through the same opening and is definitely worthwhile considering the long postoperative course of a necrotic stoma.

Separation at the mucocutaneous junction can normally be managed by conservative means with secondary healing. However, it should be noted that the risk of stenosis is proportional to the amount of secondary healing that occurs around the stoma. Secondary or delayed mucocutaneous suture is unsuccessful. The author suggests that in case of a colostomy, the abdominal wound should not be closed until the stoma is acceptable. Knowing that this violates the age-old wisdom of avoiding open bowel and open wound, this violation is justified by the smooth healing of the colostomy.

Stenosis: Stenosis is largely a complication of the old technique when the colon was pulled through the abdominal opening and cut by cautery on the first postoperative day. This procedure, learned by many active surgeons, invariably caused stenosis at the level of the skin. Digital or instrumental dilation of a narrow colostomy is usually not helpful and the trauma from dilation may even accelerate the process. Refashioning of the colostomy, preferably under general anesthesia, is the method of choice. A circumferential incision is made around the stoma a few millimetres peripheral to the mucocutaneous junction. The colostomy is dissected from the skin, the ring of skin and underlying fibrous tissue excised and the mucocutaneous junction reestablished with interrupted monofilament sutures. This procedure becomes more complicated when a part of the 
subcutaneous bowel is damaged. A sufficient amount of bowel must be raised from the abdomen to allow a mucocutaneous suture without tension. If not, separation of the suture line with concomitant secondary healing with formation of granulations and new stenosis will inevitably occur.

Colostomy hernia: Herniation around a colostomy is so common that it is considered virtually inevitable by some authors (3). Reported incidences vary between $1 \%$ and $50 \%(19,20)$. All sizes, from small areas of bulging noticed on straining to grotesque enlargements of the abdominal wall with the colostomy on the top, are seen. Colostomy hernia is particularly common when the colon has been brought out in the scar of a paramedian or iliac oblique incision. If a separate stab wound has been employed, hernias are usually smaller although they do still occur. Among measures presented to reduce the incidence of colostomy hernia are the extraperitoneal technique, meticulous suturing of the bowel to the peritoneum and bringing the colostomy through the rectus muscle instead of lateral to it.

Whittaker and Goligher (21) studied the effect of an extraperitoneal technique for colostomy construction in a nonrandomized study and observed a reduced incidence of herniation, prolapse and retraction. However, standard level of statistical significance was not reached and the extraperitoneal technique has not been widely accepted.

Meticulous suturing of the bowel to the peritoneum has also been tried by

\section{REFERENCES}

1. Brooke BN. The management of an ileostomy including its complications. Lancet 1952;ii:102-4.

2. Corman ML. Colon and Rectal Surgery, 3rd edn. Philadelphia: Lippincott, 1993.

3. Goligher JC. Surgery of the Anus, Rectum and Colon, 5th edn. Toronto: Baillere-Tindall, 1984.

4. Watts J, De Dombal F, Goligher J. Long term complications and prognosis following major surgery for ulcerative colitis. Br J Surg 1966;53:1014-22.

5. Ritchie J. Ileostomy and excisional surgery for chronic inflammatory disease of the colon: a survey of
Goligher (3) but did not result in lower incidence of hernia.

Bringing the stoma through the rectus abdominis muscle to reduce the incidence of hernia is controversial but appears reasonable. It was effective in a retrospective study by Sjödahl et al (22), and the technique is supported by the author and others (23). Bringing the terminal colon through a snugly fitting separate opening and through the rectus muscle is probably the best that can be done to avoid colostomy herniation from a surgical technical point of view.

A well fitted colostomy appliance with an attached belt is probably sufficient treatment for most small hernias.

Local repair of the abdominal wall without resiting of the colostomy is normally not effective and is disappointingly often followed by recurrence of the hernia. Resiting of the colostomy is therefore the best radical treatment for this complication (20). A method for local repair involving a synthetic mesh was recently described (24) when resiting was not appropriate. Prolapse: Sliding prolapse or retraction of a colostomy is not as serious as in case of an ileostomy because of the less irritant action of the bowel contents. However, prolapse of the stoma may lift off the appliance and cause leaks with unpleasant odour and staining of clothes.

It happens that the muscular coat of the bowel comes completely free from the attachment to the abdominal parietes and a huge prolapse, measuring 15 to $20 \mathrm{~cm}$, may occur. Patients in whom this complication is observed do

one hospital region. Gut

1971;12:528-40.

6. Roy P, Sauer W, Bearhs O, Farrow G. Experience with ileostomies. Am J Surg 1970;119:77-86.

7. Morowitz D, Kirsner J. Ileostomy in ulcerative colitis. Am J Surg 1981;141:370-5.

8. Carlstedt A, Fasth S, Hultén L, Nordgren S, Palselius I. Long-term ileostomy complications in patients with ulcerative colitis and Crohn's disease. Int J Colorectal Dis 1987;2:22-5.

9. Steinberg DM, Allan RN, Brooke BN, Cooke WWT, Alexander-Williams J. Sequelae of colectomy and ileostomy. Comparison between Crohn's colitis not form adhesions between serosal layers. Radical treatment is amputation of the protruding part of the bowel with a new attempt to suturing the bowel to the abdominal parietes, followed by mucocutaneous suture.

Miscellaneous: Peristomal abscesses, sometimes with fistula formation, may occur during healing of a stomal necrosis. A counter-incision further lateral and dorsal to the stoma may be necessary to achieve proper drainage. Laying open of the entire fistulous tract may be necessary to speed up granulation.

Recurrence of metastatic growths in the abdominal wall close to the stoma is uncommon in rectal cancer but does occur in other malignancies. It should be remembered that often the lesion that can be palpated in the stoma or through the skin only represents the tip of an iceberg of metastatic tissue and local excision with refashioning of the stoma is only rarely possible. In this situation, bringing forward a new part of the bowel as a stoma at another spot is probably the best way to help the patient.

\section{CONCLUSIONS}

The technical development of stomal appliances has reached a level where an enterostomy is compatible with an almost normal life. In the construction of an intestinal stoma extreme care should be taken to avoid all situations associated with risks for future stomal complications. Creation of a stoma is not a procedure for the unexperienced surgeon. It is our responsibility to extend the efforts to construct a well functioning enterostomy.

and ulcerative colitis. Gastroenterology 1975;68:33-9.

10. Leong APK, Londono-Schimmer EE, Phillips MS. Life table analysis of stomal complications. Br J Surg. (In press)

11. Speakman CTM, Parker MC, Northover JMA. Outcome of stapled revision of retracted ileostomy. Br J Surg 1991;78:935-6.

12. Greenstein A, Dicker ASM, Aufses A. Peri-ileostomy fistulae in Crohn's disease. Ann Surg 1983;197:179-82.

13. Suarez V, Alexander-Williams J, O'Connor H, Campos A. Carcinoma developing in ileostomies after 25 or more years. Gastroenterology 1988;95:205-8. 
14. Wexner S, Taranow D, Johansen $\mathrm{O}$, et al. Loop ileostomy is a safe option for fecal diversion. Dis Colon Rectum 1993;36:349-54.

15. Fasth S, Hultén L. Loop-ileostomy A superior diverting stoma in colorectal surgery. World J Surg 1984;8:401-7.

16. Feinberg S, McLeod R, Cohen Z. Complications of loop ileostomy. Am J Surg 1987;153:102-7.

17. Svaninger G, Nordgren S, Palselius I, Fasth S, Hultén L. Sodium and potassium excretion in patients with ileostomies. Eur J Surg 1991;157:601-5.

18. Wara P, Sorensen K, Berg V. Proximal fecal diversion: Review of ten years experience. Dis Colon Rectum 1981;24:114-9.

19. Cubertafond P, Gainant A, Barbier J, Coste G. Colostomies: indications et complications. Chirurgie 1985;111:331-41.

20. Russell KP. Parastomal hernia. World J Surg 1989;13:569-72.

21. Whittaker, Goligher JC. A comparison of the results of extraperitoneal and intraperitoneal techniques for construction of terminal iliac colostomies. Dis Colon Rectum 1976;19:342-4.
22. Sjödahl R, Anderberg B, Bolin T. Parastomal hernia in relation to site of the abdominal stoma. Br J Surg 1988;75:339-41.

23. Leslie D. The parastomal hernia. Surg Clin North Am 1984;64:407-15.

24. Alexandre JH, Bouillot JL. Paracolostomal hernia: Repair with Use of a Dacron Prosthesis. World J Surg 1993;17:680-2.

25. Goldblatt M, Corman M, Haggit R. Ileostomy complications requiring revision: Lahey Clinic Experience 1964-1973. Dis Colon Rectum 1977;20:209. 


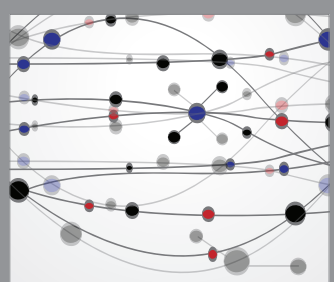

The Scientific World Journal
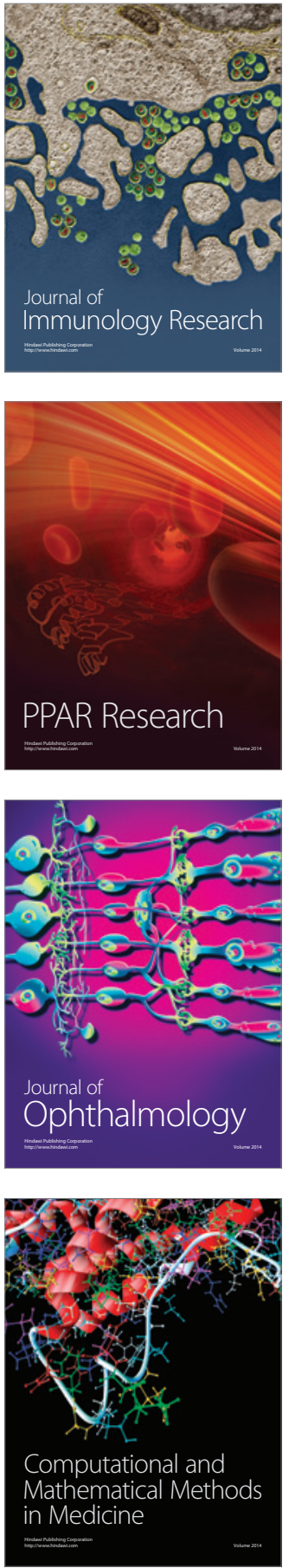

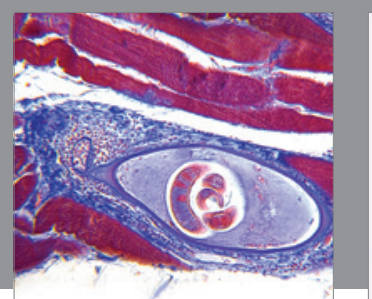

Gastroenterology Research and Practice

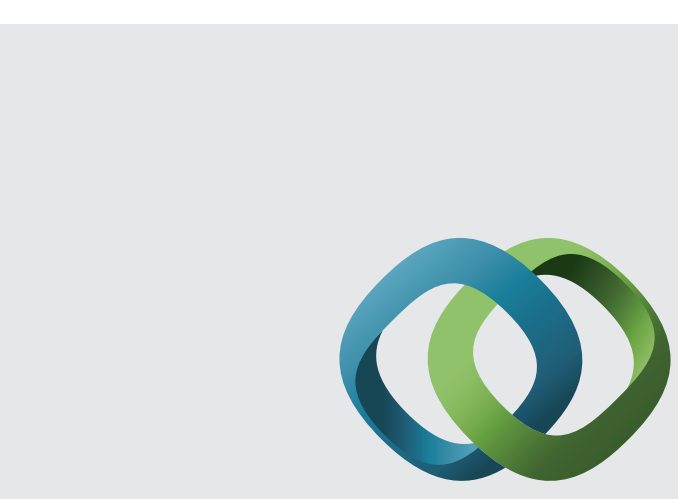

\section{Hindawi}

Submit your manuscripts at

http://www.hindawi.com
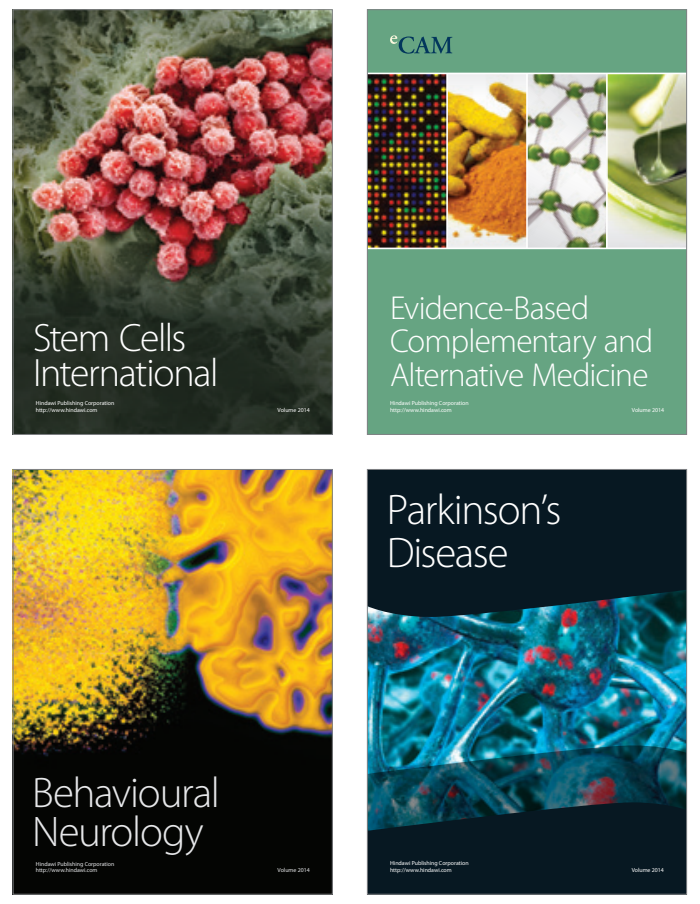
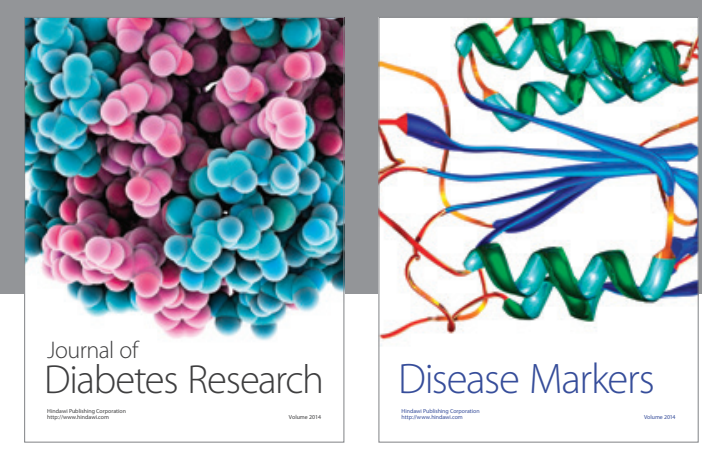

Disease Markers
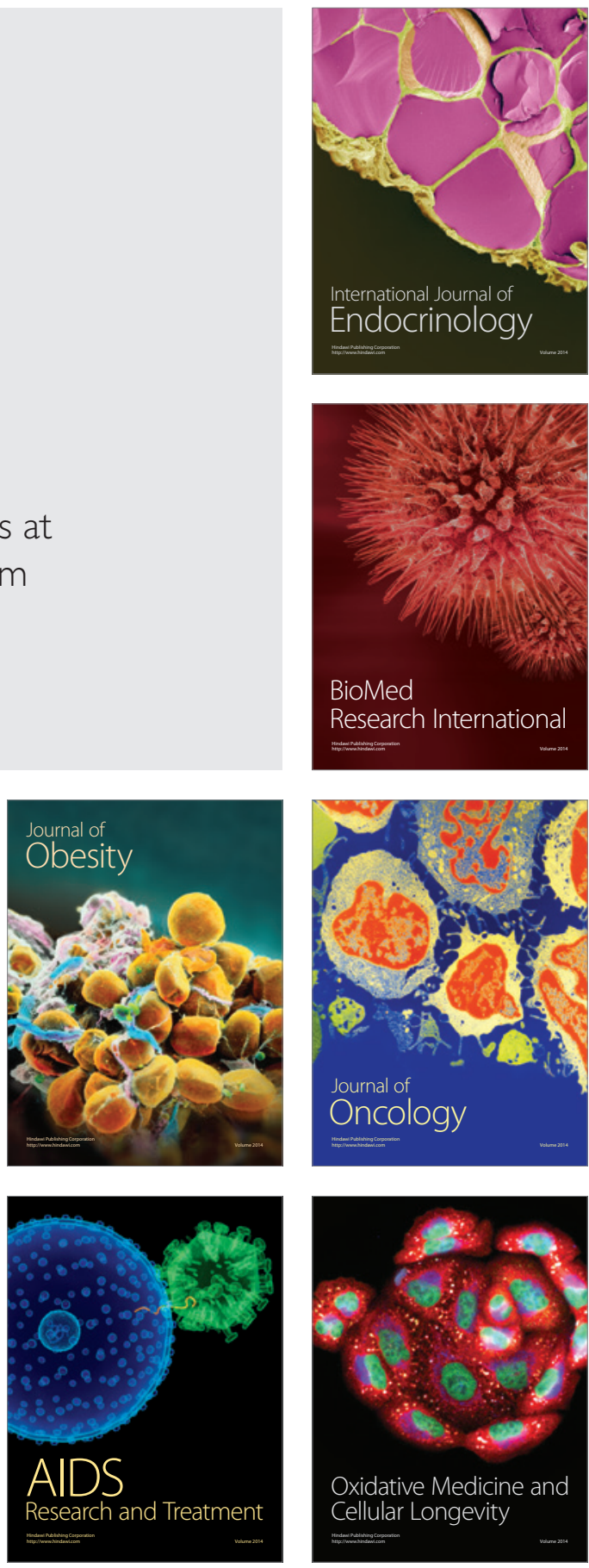